Florida International University FIU Digital Commons

\title{
The palatability of monosodium glutamate- enhanced vegetables as rated by Cuban-American older adults at a congregate meal site
}

Elissa A. Beltranena

Florida International University

DOI: $10.25148 /$ etd.FI14050491

Follow this and additional works at: https://digitalcommons.fiu.edu/etd

Part of the Dietetics and Clinical Nutrition Commons

\section{Recommended Citation}

Beltranena, Elissa A., "The palatability of monosodium glutamate-enhanced vegetables as rated by Cuban-American older adults at a congregate meal site" (2002). FIU Electronic Theses and Dissertations. 1492.

https://digitalcommons.fiu.edu/etd/1492 
FLORIDA INTERNATIONAL UNIVERSITY

Miami, Florida

THE PALATABILITY OF MONOSODIUM GLUTAMATE-ENHANCED

VEGETABLES AS RATED BY CUBAN-AMERICAN OLDER ADULTS

AT A CONGREGATE MEAL SITE

A thesis submitted in partial fulfillment of the

requirements for the degree of

MASTER OF SCIENCE

in

DIETETICS AND NUTRITION

by

Elissa A. Beltranena 
To: Dean Ronald M. Berkman

College of Health and Urban Affairs

This thesis, written by Elissa A. Beltranena, and entitled The Palatability of Monosodium Glutamate-Enhanced Vegetables as Rated by Cuban-American Older Adults at a Congregate Meal Site, having been approved in respect to style and intellectual content, is referred to you for judgment.

We have read this thesis and recommend that it be approved.
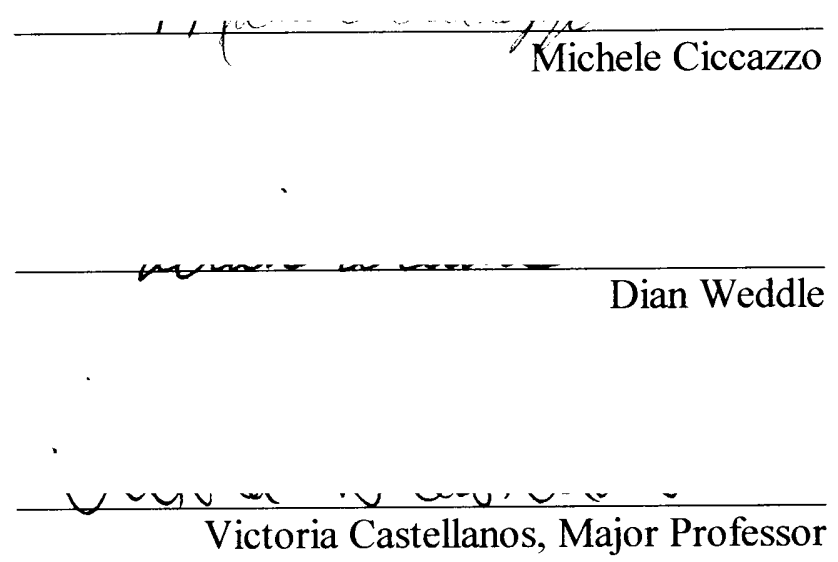

Date of Defense: March 14, 2002

The thesis of Elissa A. Beltranena is approved.

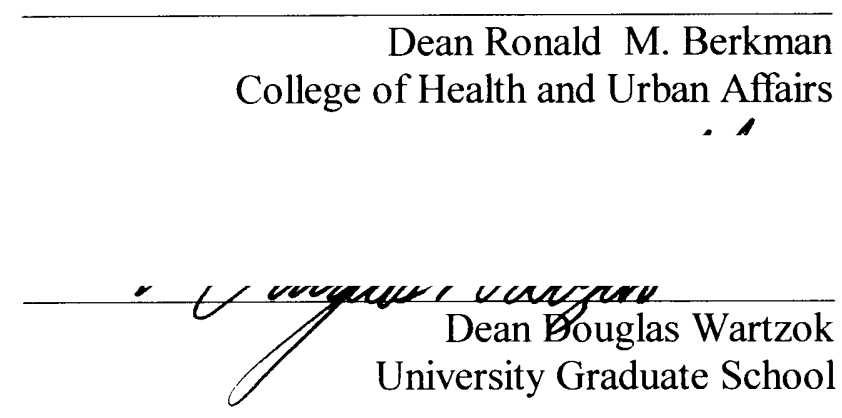

Florida International University, 2002 


\section{DEDICATION}

I dedicate this thesis to God. Without His love, strength and guidance none of this would have been possible. I also dedicate this thesis to my parents, who supported, encouraged, and loved me unconditionally; to Christian, whose love and patience gave me the strength to keep going; to my sisters, who are such an important part of my life; and to all my family and friends who encouraged me. 


\section{ACKNOWLEDGMENTS}

I would like to thank the members of my committee, Dr. Michele Ciccazzo and Dr. Dian Weddle for their support, patience and guidance through this hard process. Your input was very valuable and helpful for the completion of this project. I would also like to thank South West Social Services for allowing me to use their facilities for this study and for all the help they provided in order to make this possible. I would especially like to thank my major advisor, Dr. Victoria Castellanos. Her experience, hard work and dedication in guiding me to complete this thesis taught me how to persevere and strive for excellence in everything I do. 


\begin{abstract}
OF THE THESIS
THE PALATABILITY OF MONOSODIUM GLUTAMATE-ENHANCED

VEGETABLES AS RATED BY CUBAN-AMERICAN OLDER ADULTS

AT A CONGREGATE MEAL SITE
\end{abstract}

by

Elissa A. Beltranena

Florida International University, 2002

Miami, Florida

Professor Victoria Castellanos, Major Professor

The purpose of this study was to investigate the efficacy of using monosodium glutamate (MSG) as a means to increase palatability and prospective consumption of vegetables at a congregate meal site with Cuban-American clients. Thirty to 32 subjects participated in hedonic testing each day. MSG-enhanced ( $2 \mathrm{~g} \mathrm{MSG} / 500 \mathrm{~g}$ vegetable) and non-enhanced beets, string beans, carrots and peas were evaluated for palatability, preference and prospective consumption. Results showed that MSG significantly increased both palatability and prospective consumption of string beans $(p s<.05)$ but not of the other 3 vegetables tested. These findings provide some evidence that MSG can be used to increase the palatability of vegetables served at congregate meal sites. However, these results suggest that older adults may not find the palatability of some vegetables to be improved by MSG and that optimal flavor enhancement cannot be achieved by adding the same amount of MSG to every vegetable. 
I. INTRODUCTION.................................................. 1

Research Hypotheses............................................... 5

References........................................................... 6

II. LITERATURE REVIEW ........................................... 8

Malnutrition in the Elderly........................................... 9

Dietary Variety in the Older Adults.................................. 11

Loss of Taste and Smell in the Elderly................................. 13

Taste and Odor Enhancement......................................... 14

MSG Safety.................................................... 18

The Effect of Flavor Enhancement on Food Intake of Older Adults......... $\quad 20$

Congregate Meal Sites................................................ 25

Vegetable Consumption in Hispanic Americans........................... 27

Summary ........................................................ 29

References........................................................ 30

III. THE PALATABILITY OF MONOSODIUM GLUTAMATEENHANCED VEGETABLES AS RATED BY CUBAN-AMERICAN OLDER ADULTS AT A CONGREGATE MEAL SITE. ................. 35 Introduction........................................................ 36

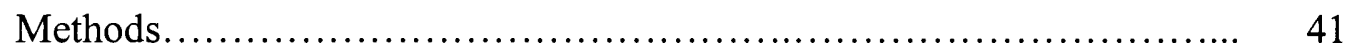

Results......................................................... 44

Discussion..................................................... 45

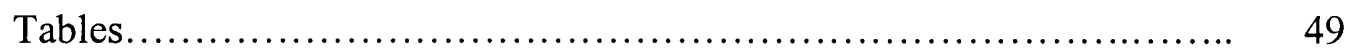

References.................................................... 51

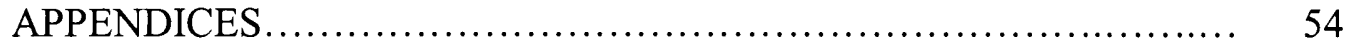


CHAPTER I

INTRODUCTION 
Taste and odor are the key determinants of the palatability of foods. It is important to understand the hedonic characteristics of foods preferred by older adults as this group is known to be at nutritional risk (Wurtman et al, 1988).

There are a number of variables that affect food selection and, thus, nutritional status. These include social factors, such as level of education, financial status, and living arrangements (Ferrini and Ferrini, 2000). Physiological and psychological factors can also decrease appetite in older adults. Depression, confusion, use of multiple medications, and illnesses of old age, such as cognitive impairment, arthritis and other motor impairments, and dental problems can all decrease appetite thereby placing the older adult at nutritional risk (Wurtman, 1988).

In addition to the factors discussed above, studies have found that the senses of taste and smell start to decline by age 60 (Schiffman, 1997). Chemosensory dysfunction is classified by ageusia (absence of taste), hypogeusia (diminished sensitivity of taste), dysgeusia (distortion of normal taste), anosmia (absence of smell), hyposmia (diminished sensitivity of smell), and dysomia (distortion of normal smell) (Schiffman, 1997). Chemosensory changes can alter amount of food consumed as well as food selection (Schiffman, 1983).

Choosing a variety of foods is thought to contribute to a healthy eating pattern by providing the micronutrients required for optimum health (Drewnowski, 1997). Unfortunately, the chemosensory deficits associated with old age may result in consumption of a more monotonous diet by this group (Rolls, 1986). Failure to stimulate older adults consuming a monotonous diet to eat a wider variety of foods could lead to inadequate nutrition (Pelchat and Schaefer, 2000). In addition to reduced dietary variety, 
deterioration of gustatory and olfactory perception in older adults may also contribute to intake of insufficient amounts of food. Risk of malnutrition in older adults increases with loss of appetite, decrease of usual weight and increased weight change in the previous year (Shatenstein et al, 2001; Lumbers et al, 2001).

Although chemosensory deficits are generally not reversible, sensory interventions including intensification of taste and odor can potentially compensate for perceptual losses (Schiffman, 1983, 2000) and has been suggested as one mechanism to increase food intake (Schiffman and Warwick, 1993). In her 1997 review paper Schiffman states "amplification of the flavor levels in foods to optimal concentrations for the elderly can improve food enjoyment, have a positive effect on food intake, and foster appropriate nutritional intake" (Schiffman, 1997).

Monosodium glutamate (MSG) is the sodium salt of the amino acid glutamic acid and is commonly used for flavor amplification in processed foods. Its unique taste is called "umami" in Japanese, which means delicious, and is used to describe the taste of MSG as well as the meaty taste of certain fish and broths. It is suggested to be a "protein taste” (Bellisle, 1999; Maga 1983). A number of studies have successfully used commercial flavors and MSG in the preparation of meals for older people to enhance smell and taste properties and to improve palatability (Schiffman, 1983; Schiffman and Warwick, 1993). Because MSG enhances the flavor of food but contains less sodium by weight than $\mathrm{NaCl}$ (common table salt), the addition of MSG to foods has the potential to allow consumers to enjoy a flavorful diet while at the same time decreasing their sodium intake (Yamaguchi and Takahashi, 1984). 
Older Hispanic adults are among the most rapidly growing demographic group in the United States. The Hispanic population has increased by 57.9 percent since 1990. Currently, Cubans constitute 3.5 percent of the Hispanic population in the US and two thirds of all Cubans reside in the state of Florida (U.S. Census Bureau, 2001).

Hispanics are at high risk for developing certain chronic diseases. Eating a more healthful diet, including adequate vegetable intake, may reduce risks of developing these conditions. Bartholomew et al, 1990 reported a low intake of all vegetables among elderly Hispanics, and other investigators have reported similar finding specifically for Puerto Ricans, Dominicans and Cubans (Shea et al, 1993).

Congregate meal sites are government supported facilities that provide food for low-income elderly. They provide a minimum of one hot meal per client for a minimum cost (TCSG, 2001). There are a number of congregate meal sites in South Florida that serve a predominantly Hispanic clientele. Studies have reported that ethnicity is the major variable influencing food intake among low-income, free-living Hispanic older people (Bartholomew et al, 1990). There are anecdotal reports of low vegetable intake at some of these sites, which suggest that the vegetables being served do not adequately meet the population's needs and preferences.

The purpose of this study was to investigate the efficacy of using the flavor enhancer, monosodium glutamate (MSG), as a means to increase palatability and prospective consumption of vegetables by older Cuban Americans at a congregate meal site in South Florida. 


\section{RESEARCH HYPOTHESES}

The research hypotheses for this study were the following:

1. Hispanic congregate meal site clients will give a higher palatability rating to the MSG enhanced vegetables compared to the non-enhanced vegetables.

2. In a forced-choice preference test, Hispanic congregate meal site clients will prefer the MSG enhanced vegetable to the non-enhanced vegetable.

3. Hispanic congregate meal site clients will indicate a willingness to eat more vegetables when they are enhanced with MSG compared to when the vegetables are not enhanced. 


\section{REFERENCES}

Bartholomew A, Young E, and Hazuda H. (1990). Food frequency intakes and sociodemographic factors of elderly Mexican-Americans and non-Hispanic whites. $J$ Am Diet Assoc, 90, 1693-1696.

Bellisle F. (1999). Glutamate and the UMAMI taste: sensory, metabolic, nutritional and behavioral considerations. A review of the literature published in the last 10 years. Neur Biobehav Rev, 23, 423-438.

Drewnowski A. (1997). Taste preferences and food intake. Ann Rev Nutr, 17, 237 -253 .

Ferrini AF, and Ferrini RL. (2000). Health in the later years. ${ }^{\text {rd }}$. ed. Boston: McGraw Hill. 502pp.

Lumbers M, New SA, Gibson S, and Murphy MC. (2001). Nutritional status in elderly female hip fracture patients: comparison with an age-matched home living group attending day centers. J Nutr, 85, 733-740.

Maga JA. (1983). Flavor potentiators. Crit Rev Food Sci Nutr, 18, 231-312.

National Center for Chronic Disease Prevention and Health Promotion (CDC). (2002). Chronic Disease Prevention: The burden of chronic diseases and their risk factors. National and State Perspectives 2002. Available at: http://apps.nccd.cdc.gov/BurdenBook/ Accessed March 15, 2002.

Pelchat ML, and Schaefer S. (2000). Dietary monotony and food cravings in young and elderly adults. Physiol Behav, 3, 353-359.

Rolls BJ. (1986). Sensory-specific satiety. Nutr Rev, 44, 93-101.

Schiffman, SS. (1983). Taste and smell in disease. N Engl J Med, 22, 1275-79 and 1337-1343.

Schiffman SS, and Warwick ZS. (1993). Effect of flavor enhancement of foods for the elderly on nutritional status: food intake, biochemical indices and anthropometric measures. Physiol Behav, 2, 395-402.

Schiffman SS. (1997). Taste and smell losses in normal aging and disease. J Am Med Assoc, 16, 1357-1362. 
Schiffman SS. (2000). Intensification of sensory properties of foods for the elderly. $J$ Nutr, 4S, 927S-930S.

Shatenstein B, Kergoat MJ, and Nadon S. (2001). Weight change, nutritional risk and its determinants among cognitively intact and demented elderly Canadians. Can J Public Health, 92(2), 143-149.

Shea S, Melnik T, Stein AD, Zansky SM, Maylahn C, and Basch CE. (1993). Age, sex, educational attainment, and race/ethnicity in relation to consumption of specific foods contributing to the atherogenic potential of diet. Prev Med, 22, 203 -218 .

The Center for Social Gerontology (TCSG). (2001). Unofficial compilation of Older Americans Act Revisions. Avilable at: http://www.tcsg.org/law/oaa/reauth.htm. Accessed March 14, 2002.

U.S. Census Bureau (2001). The Hispanic Population: Census 2000 Brief. U.S. Department of Commerce. Economics and Statistics Administration. Washington, DC.

Wurtman JJ. (1988). Carbohydrate craving, mood changes and obesity. J Clin Psych, (Suppl), 49, 37-79.

Wurtman JJ, Lieberman H, Tsay R, Nader T, and Chew B. (1988). Calorie and Nutrient intakes of elderly and young subjects measured under identical conditions. J Gerontol, 43, B174-180.

Yamaguchi S, and Takahashi C. (1984). Interactions of monosodium glutamate and sodium chloride on saltiness and palatability of a clear soup. J Food Sci, 49, 82-85. 
CHAPTER II

LITERATURE REVIEW 


\section{MALNUTRITION IN THE ELDERLY}

Up to 25 percent of elders living in the United States have been estimated to be malnourished (Peter, 1993). Risk of malnutrition increases with loss of appetite, decrease of usual weight and increased weight change in the previous year (Shatenstein et al, 2001; Lumbers et al, 2001). Population based nutrition surveys have shown a gradual decline in energy intake for older adults, which may result in an increased risk for malnutrition (Koehler, 1994).

Inadequate vegetable intake has also been reported among this population. The recommended daily servings of fruits and vegetables for the elderly population are 5 or more, according to the modified Food Guide Pyramid for people over 70 years (Center of Nutrition Communication, 1999). According to National Center for Chronic Disease Prevention and Health Promotion, in $199981 \%$ of men and $73 \%$ of women in the United States reported eating fewer than five servings of fruits and vegetables per day (CDC, 2002). Specifically, $81.5 \%$ of Hispanics in the state of Florida reported eating fewer than five servings of fruits and vegetables per day (CDC, 2002). Poor nutritional intake and status is considered a key determinant of morbidity and mortality (Lumbers et al, 2001).

There are a number of variables that affect food selection and consequent nutritional status. Physiological factors, such as disability or limitations in activities of daily living secondary to the disease process (i.e. cancer and Alzheimer's disease), can severely affect mobility, energy level, and visual acuity, which decrease interest in eating and ability to shop for and prepare food (Ferrini and Ferrini, 2000; de Groot et al, 2000). Special dietary regimens for disease treatment or management involving restriction of salt, sugar and fats, may prevent people from eating foods they like (Betts, 1988; Kohrs, 
1982). Older adults are also less efficient in their responses to regulatory challenges and are less likely to report hunger or thirst, which means that they are less aware of their physiological needs and may forget to eat and drink from time to time (Rolls, 1989).

Drugs taken for disease management can also affect nutritional intake and diminish appetite by causing nausea and vomiting and by altering taste and smell (Schiffman, 1997). Pharmacological and surgical interventions, radiation, and environmental exposure also contribute to sensory declines and appetite changes. These chemosensory deficits can alter the amount of food consumed as well as food selection (Schiffman 1983, 1997; Griep, 1996; Rolls, 1997).

Psychological factors, such as a person's emotional state, affect motivation to shop and prepare nutritious meals. Anxiety and depression can cause either diminished appetite or overeating (Ferrini and Ferrini, 2000). Social factors, including poverty, lack of help with shopping, and solitary meals, also play a role in reducing food intake in older people (Wurtman, 1988). This can also be affected by living arrangements. Those living alone have been shown to have the poorest diets (Ferrini and Ferrini, 2000).

Financial status and education influence the quality of food purchased and motivation to eat healthy. Level of education and knowledge about nutrition affects people's food choices and methods of food preparation; elders with a high education level generally have fewer nutrient deficiencies compared to those with less education (Ferrini and Ferrini, 2000). Elders who rely on economic assistance programs are more likely to have poor nutritional intake. The availability of community nutrition programs, distance from shopping facilities, transportation, and geographical location all affect food choices and nutritional status (Ferrini and Ferrini, 2000). 
In conclusion, it appears that physiological, psychological, and social factors, level of education, financial status, and living arrangements all affect nutritional status in older adults (Ferrini and Ferrini, 2000). Such an understanding of these determinants of nutritional intake may be helpful in the early detection and prevention of malnutrition in the elderly (de Groot, 2000).

\section{DIETARY VARIETY IN THE OLDER ADULTS}

Choosing a variety of foods is thought to improve eating patterns by providing the micronutrients required for optimum health (Drewnowski, 1997). The study of food variety focuses on the quality of the total diet rather than on individual foods. Eating a wide variety of foods is regarded as an integral component of a healthful eating style. In a study conducted by Drewnowski et al (1997), it was suggested that greater dietary variety tends to be associated with increased consumption of vegetables and fruit. In this study, increased variety was associated with increased consumption of vitamin $\mathrm{C}$ and fiber, and reduced consumption of sugar, sodium and saturated fat (Drewnowski et al, 1997).

It has been argued that sensory losses may be responsible for reduced dietary variety in old age (Rolls, 1986; Drewnowski et al, 1997). There is some evidence that dietary variety and quality decline with advancing age. Dietary intake analyses of participants in the 1977-78 Nationwide Food Consumption Survey showed that the oldest people consumed the lowest number of different foods (Fanelli and Stevenhagen, 1985).

Researchers have used studies of sensory specific satiety to explain why dietary variety might decrease with age (Rolls, 1986). Usually, following consumption of a particular food, a person will report a decrease in the subjective pleasantness of the 
appearance, smell, texture, and taste of the food that lasts for at least one hour after eating (Rolls, 1986). This subjective report of change in the pleasantness of palatability is called sensory-specific satiety (Rolls, 1986). The likelihood of that food to be chosen again in the short term is reduced. A decrease in sensory-specific satiety would be expected to be associated with both consumption of monotonous diets and a failure to increase the amount consumed in response to variety in the diet (Rolls, 1986).

A study conducted by Rolls and Macdermont (1991) compared sensory-specific satiety and sensory perception in adolescents, young adults, and older adults. Elderly participants failed to show a decrease in the pleasantness of the taste of yogurt following either ad libitum access to yogurt or a $300 \mathrm{~g}$ fixed load of yogurt. Also, desire to eat the yogurt and pleasantness of the texture of the food did not diminish following the fixed load in the elderly participants. Although a decline in sensory processing and taste acuity might explain these results, this study found no correlation between sensory impairment and diminished sensory-specific satiety. Another explanation could be that elderly people are more resistant to changes of any kind, and it may be that aging processes alter appetite regulation including sensory specific satiety (Rolls and Macdermont, 1991).

In conclusion, although inadequate intake of some essential nutrients has been linked to restricted food choices (Fanelli and Stevenhagen, 1985), there continues to be little evidence linking dietary variety to overall dietary adequacy or to specific health outcomes in older adults. More studies need to be done in order to assess variety and assess its effect on the quality of the total diet (Drewnowski et al, 1997). 


\section{LOSS OF TASTE AND SMELL IN THE ELDERLY}

The gustatory system is the system by which taste is perceived and interpreted by the brain; the olfactory system is the system by which we smell (Weiffenbach, 1984). These both are part of the limbic system, which is a group of subcortical structures (including the hypothalamus, the hippocampus, and the amygdala) of the brain that are especially concerned with emotion and motivation (Merriam-Webster, 1999).

The sense of taste is initiated through the taste buds, which are receptors located on the tongue. The gustatory stimuli interact with these receptors, which results in depolarization of the receptor and transmission of the electrical signal. Taste transduction involves sodium and potassium ion channels and two second-messenger systems. Information is transmitted by electrical signals to the medulla by branches of the cranial nerves that innervate the tongue (Chorda Tympani [CT], Glossopharyngeal [GL], Greater Superficial Petrosal [GSP], and Lingual [V] nerves). The sensory information is then processed and sent to the gustatory cortex (Duffy, 1999).

Taste and odor are the key determinants of the palatability of foods. Consumer and marketing studies show that taste is the key influence on food selection (Drewnowski, 2000). Deterioration of gustatory and olfactory perception is a cause for

concern in the elderly. Clinical and laboratory studies have found taste and smell start to decline by age 60 and the decline is more severe in persons over 70 years of age (Schiffman, 1997). Chemosensory dysfunction is classified by the following: ageusia (absence of taste), hypogeusia (diminished sensitivity of taste), dysgeusia (distortion of normal taste), anosmia (absence of smell), hyposmia (diminished sensitivity of smell), and dysomia (distortion of normal smell) (Schiffman, 2000). 
Changes in the gustatory system associated with increasing age do not appear to be as marked as for the olfactory system. Taste losses associated with aging are most commonly found at the threshold level. Threshold is sensitivity to a particular chemosensory stimulus and represents the lowest concentration needed to elicit a sensation or to recognize a sensation. Salt thresholds show age-related elevations, while sucrose thresholds appear stable across age cohorts. For example, it has been reported that elderly require a 2 or 3 -fold higher concentration of salt in order to detect it in tomato soup (Stevens, 1989; Kimura, 1993). Within bitter compounds, the degree of age related threshold elevation also varies. The elderly are able to show elevated thresholds for tastes in taste mixtures (Duffy, 1999).

Chemosensory deficits associated with age generally cannot be reversed and may reduce the quality of life, increase the risk from food poisoning, and lead to inadequate nutrition, especially in the sick elderly (Schiffman, 1983, 1993). Sensory interventions such as flavor enhancement can, in theory, compensate for age-related perceptual losses (Schiffman, 1983).

\section{TASTE AND ODOR ENHANCEMENT}

Flavors are mixtures of odorous molecules that can be extracted directly from natural foods or can be synthesized in the laboratory after chromatographic and mass spectrographic analysis of natural products. Often they contain nonvolatile compounds, such as amino acids or salts, which induce taste and/or somatosensory stimulation (Schiffman, 2000). 
Traditional methods of increasing odor and taste sensations use spices, herbs and salt. These add different flavors to the food rather than intensify the original properties of the food. Flavors, unlike spices, do not irritate the mouth and stomach (Schiffman, 2000). Flavors probably exert their effect by increasing the number of molecules that interact with receptors on chemosensory membranes in the nose and oral cavities. This intensification induces more salivation, produces greater stimulation of the olfactory and limbic system of the brain, and promotes immune function (Schiffman, 2000).

Several studies have used commercial flavors and monosodium glutamate (MSG) in the preparation of meals for the elderly with the goal to enhance smell and taste properties and improve palatability (Schiffman, 1983, 1993; Bellisle et al, 1991). MSG is the sodium salt of the amino acid glutamic acid. Its unique taste is called "umami" in Japanese, which means delicious. "Umami" is also used to describe the meaty taste of certain fish and broths. It is suggested to be a "protein taste" (Bellisle, 1999; Maga, 1983). It has been noted that this taste does not fall within what has traditionally been thought of as the four tastes; sweet, sour, salty and bitter (Schiffman, 1997). MSG is often used commercially in mixtures with certain 5'-ribonucleotides (GMP and IMP) because they have synergistic sensory stimulation effects (Wurtman et al, 1988; Schiffman, 1994).

Glutamic acid, the predominant molecule in MSG, is the most abundant amino acid contained in the diet. It is found at high levels in fish like cod and salmon, vegetables like green peas, corn, spinach, beets, tomatoes, carrots, onions and peppers, in dairy products such as milk (both human and cow's milk) and parmesan cheese, and finally in eggs and meats. The average daily intake of glutamic acid in the United States 
is estimated to be 0.2 to $0.5 \mathrm{~g}$. Glutamate is known to be absorbed into the enterocyte in the gut by active transport. A large part of glutamic acid is metabolized in the enterocyte, resulting in very small amounts of glutamate leaving the gut and elevated plasma levels of the transamination product alanine (Bellisle, 1999).

Schiffman et al. (1994) conducted an experiment to determine the concentrations at which young and elderly subjects were able to detect and recognize MSG in various foods. She found that detection thresholds for MSG in foods were 2.8 times higher in older people than in young subjects. Results showed that older adults did not show a preference for a specific concentration of MSG. Rather, the preferred MSG concentration was different for each food $($ corn $=0.069 \%$, chicken broth $=1.105 \%$, cubed steak $=$ $0.017 \%$ weight/weight) (Schiffman et al, 1994). The preferred concentrations of MSG in foods tended to be lower than the level at which MSG is detected in foods but above the level detected in water. The mechanism by which this is the preferred level of MSG is not fully understood, but it is believed that MSG might react with food chemicals and form new taste compounds (Schiffman et al, 1994). For example, Fuke and Konosu found that it is the combination of glutamate with other food ingredients that produces the characteristic tastes of seafood, meat and tomatoes (Fuke and Konosu, 1991).

Bellisle et al (1989) conducted a four-week food intake study with 36 young French men and women. Two experimental foods (spinach mousse and beef jelly) were developed. These had familiar flavor but unfamiliar aspects and were prepared either without MSG or with 0.3 to $1.2 \%$ MSG. These foods were meant to be of medium palatability so that adding MSG could exert some effect. The amount ingested of each food was measured over successive weekly presentations. There were 3 test groups, each 
was repeatedly presented the same level of $\operatorname{MSG}(0,0.6$, or $1.2 \%)$. Results showed that the foods enhanced with $0.6 \%$ MSG were consumed in greater amounts over 4 weeks of repeated exposure, indicating an increasing stimulation to eat with repeated exposure and sustained palatability of these foods over time. The addition of $1.2 \%$ MSG increased meal size initially, but there was no difference compared to baseline after 4 weeks. This indicates an effect of immediate positive palatability but no stimulation to eat with repeated exposure (Bellisle et al, 1989).

In a second study, in 64 institutionalized patients (average age $84 \mathrm{yrs}$ ), Bellisle et al. (1991) evaluated the effect of enhancing the soup and starch dish with $0.6 \%$ MSG on two different menus. An initial increase in meal intake was observed using this concentration but general intake decreased over repeated exposure in foods when both enhanced and non-enhanced with MSG (Bellisle, 1991).

The previous two studies show that differences in chemosensory functions in older adults compared to younger adults cause a different response to MSG enhanced foods. In the elderly subjects, general intake decreased over repeated exposure in certain foods when presented with both MSG-enhanced (with $0.6 \% \mathrm{MSG}$ ) and non-enhanced conditions, while young subjects sustained palatability and consumed greater amounts of foods enhanced with 0.6\% MSG over a 4-week period (Bellisle et al, 1989, 1991).

MSG contains less sodium by weight than common table salt $(\mathrm{NaCl})$. This provides a benefit since the addition of MSG to foods could allow consumers to enjoy a palatable diet while at the same time using less salt and decreasing their sodium intake. In clear soup tasted by Japanese panelists, the optimal levels of MSG and $\mathrm{NaCl}$ were estimated as $0.38 \%$ and $0.81 \%$, respectively. When $\mathrm{MSG}$ and $\mathrm{NaCl}$ were used in 
combination, more MSG was necessary when the $\mathrm{NaCl}$ concentration was lower and less MSG when $\mathrm{NaCl}$ concentration was higher (Yamaguchi and Takahashi, 1984). In American young adults tasting a Turkish type ready-made soup, the preferred concentration of MSG was found to be $0.33 \%-0.38 \%$ and $0.83 \%-0.87 \% \mathrm{NaCl}$. Without affecting palatability, a $40 \%$ sodium reduction was reached when $0.6-0.8 \%$ MSG was added (Altug, 1993).

Taken together, the studies that have evaluated MSG detection thresholds and concentration preferences in older and young adults have found that detection thresholds tend to be higher for older adults. They also found that the older adults tended to prefer a higher concentration of MSG in their enhanced foods (Altug, 1993; Yamaguchi and Takahashi, 1984; Bellisle et al, 1989, 1991; Schiffman et al, 1994).

\section{MSG SAFETY}

The Food and Drug Administration (FDA), has classified MSG as "generally recognized as safe" or GRAS. The FDA has concluded that MSG poses no threat to the general public but that reactions of brief duration might occur in some people (FDA/ Gov Doc, 2001).

Organizations such as the Joint FAO/WHO Expert Committee on Food Additives (JECFA) have evaluated the data on the safety of glutamates (L-glutamic acid and its sodium, potassium, calcium, magnesium, and ammonium salts). The Committee noted in 1988 that there was an elevation of glutamate levels in systemic circulation only after extremely high doses given by gavage ( $>30 \mathrm{mg} / \mathrm{kg}$ body weight). Conventional toxicity studies using dietary administration of MSG in several species did not reveal any specific 
toxic or carcinogenic effects, nor were there any adverse outcomes in reproduction and teratology studies. The safety evaluation led JECFA to conclude that the total dietary intake of glutamates arising from their use at levels necessary to achieve the desired sensory effect do not represent a hazard to health. For that reason, the establishment of an Acceptable Daily Intake (ADI) in numerical form was not deemed necessary and the status of "ADI not specified" was allocated to L-glutamic acid and the monosodium, potassium, calcium, and ammonium salts (Walker, 2000). The European Community Scientific Committee for Food reached conclusions similar to the JECFA in 1991 (European Community, 1991; WHO, 1988).

Although MSG has GRAS status, it has been determined that some people may be sensitive to MSG. The most common reactions are headache, nausea, vomiting, drowsiness, weakness, burning sensation in the back of the neck, chest and forearms, numbness in the back of the neck, rapid heartbeat, worsening of asthma, and chest pain (FDA/ Gov Doc, 2001). These tend to occur within one hour after eating 3 grams or more of MSG on an empty stomach or without other food (FDA/ Gov Doc, 2001). Severe, poorly controlled asthma may be a predisposing medical condition for MSG symptom complex (FDA/ Gov Doc, 2001).

A multicenter, multiphase, double-blind, placebo-controlled study with a crossover design was performed to determine if large doses of MSG given without food would elicit more symptoms than a placebo in individuals who believe they react adversely to MSG. Four different protocols (A, B, C and D) were conducted, with MSG being administered without food in three of them. Out of 130 subjects in protocol A, $38.5 \%$ reacted only to MSG. Less than half of these responded similarly in protocol B 
where doses of MSG were increased to $5 \mathrm{~g}$, suggesting inconsistency in the response. Only 2 of the subjects that reacted in protocol B responded to both MSG challenges but not to the placebo challenge in protocol $\mathrm{C}$; however, their symptoms were not reproducible or not the same in all protocols. In protocol D, these two subjects were challenged three times with placebo and three times with $5 \mathrm{~g}$ of MSG in the presence of food. Both responded to only one of the protocol D MSG challenges. In conclusion, this study demonstrated neither persistent nor serious effects from MSG ingestion, and the responses that were observed were not consistent on retesting (Geha, 2000). A second randomized, double blind, crossover study confirmed these results by finding that MSG presented in capsules, so as to bypass sensory stimulation, did not induce adverse affects more often than placebo in "sensitive" volunteers (Tarasoff, 1993).

In conclusion, using MSG as a food flavor enhancement agent poses no threat to most individuals. However, sensitive or allergic people should be cautious when using this product. Its use is discouraged in these people as well as in subjects with poorly controlled asthma who may be predisposed for MSG symptom complex (FDA/ Gov Doc, 2001; Geha, 2000).

\section{THE EFFECT OF FLAVOR ENHANCEMENT ON FOOD INTAKE OF OLDER} ADULTS

A large portion of the elderly population experiences a loss in taste and smell perception. Whether or not chemosensory deficits can and do lead to inadequate dietary intake, with significant nutritional consequences, is controversial (Schiffman, 1993; Mattes, 2002). Concrete evidence, that flavor enhancement either increases food intake 
or positively impacts nutritional status, is currently lacking (Mattes, 2002). Several studies have attempted to increase food intake in older adults through the use of flavor enhancement.

Schiffman and Warwick (1993) studied 39 elderly retirement home residents, mean age 84.6 years. Six flavors, selected by a panel of older adults belonging to the Flavor and Extract Manufacturers' Association (FEMA), were utilized throughout the study: roast beef, ham, natural bacon, prime beef, maple and cheese. Flavors were incorporated into the foods by mixing the powder with a small amount of water. Group 1 ate a non-enhanced diet for 3 weeks and group 2 the enhanced diet, and then the diets were reversed (Schiffman and Warwick, 1993).

Food consumption was measured at every meal for 5 days of the week. Subjects were served a set tray in a dining hall, and all received identical trays. All food portions were measured to the nearest $0.1 \mathrm{~g}$ prior to serving and immediately after the meal, and the amount eaten determined by subtraction. Weight, height, midarm circumference and triceps skinfold thickness were also measured (Schiffman and Warwick, 1993).

Results showed a non-statistically significant trend for an increased intake of 20 out of the 30 flavor enhanced foods. However, it is difficult to assess the nutritional impact of this trend, as it did not significantly shift the overall dietary nutrient profile. Calorie, protein, carbohydrate, fat, and micronutrient intakes were almost identical in the enhanced and un-enhanced conditions. Body weight also remained relatively constant for both conditions compared to baseline. For group 1, body weight had an increase of $0.7 \mathrm{~kg}$ for the un-enhanced condition and a decrease of $0.2 \mathrm{~kg}$ in the enhanced condition. Group 2 showed a $0.1 \mathrm{~kg}$ increase for the un-enhanced condition and a decrease of $0.8 \mathrm{~kg}$ for the 
enhanced condition. Improvement of immune status and grip strength were reported under conditions of flavor enhancement, although these findings are difficult to interpret since nutrient intake was not different from the un-enhanced condition (Schiffman and Warwick, 1993).

In a review paper, Schiffman (1998) reported results from some of her own unpublished original research. She indicated that the addition of MSG to foods improved intake up to $20 \%$ in 40 out of 43 patients in a hospital setting, although the actual data from this study are not provided. From this account, the subjects in this study were selected by having clinical manifestations of malnutrition, including a recent weight loss of $6 \%$ or more and/or were below average weight for height and age. Food weight was measured before and after eating on two consecutive days. Although the methodology is not described, Schiffman reports that the levels of MSG added to foods were individualized on the basis of each patient's taste and odor thresholds. In addition to reports of increased food intake, the review paper also indicates that sensory enhancement of foods over a week or more resulted in an improvement in plasma protein levels, although, again, the data were not provided. Lastly, this author reported that an open-ended questionnaire suggested that sensory enhancement of foods with MSG and flavors can improve satisfaction in healthy elderly (Schiffman, 1998). When considering this report it is important to note that none of this data has been published in an original research article.

Mathey et al (2001) conducted an experiment to determine whether the addition of ready-to-use flavor enhancers to the cooked meals over 16 weeks would lead to an increase in food consumption and thereby provide nutritional benefits to elderly nursing 
home residents. Body weight was measured as an index of nutritional status before and after the study. Four flavor powders were selected. These were sprinkled over the whole main dish (including carbohydrate-rich components and vegetables) just before meal delivery. Dietary intake data were collected using a combination of 3-day record and food weighing methods before and after the 16-week intervention. Subjects also responded to a 29-item questionnaire about their feelings of hunger, appetite, and their taste and smell perception (Mathey et al, 2001).

Results from this study showed a statistically significant increase in total energy of $133 \mathrm{~kJ}$ (32 kcal) per meal, and an average body weight increase of $1.1 \mathrm{~kg}$ in the flavor group after the 16- week intervention period. The control group had a non-significant energy increase of $85 \mathrm{~kJ}$ ( $20 \mathrm{kcal})$ per meal and an average body weight decrease of 0.3 $\mathrm{kg}$. However, total daily intake for both flavor and control groups declined after the 16week intervention, $-208 \mathrm{~kJ}(-50 \mathrm{kcal})$ and $-485 \mathrm{~kJ}(-116 \mathrm{kcal})$ respectively. Results from the questionnaire showed higher scores for daily feelings of hunger and present smell perception after the 16-week intervention. This study suggests that while the addition of flavors may increase the energy intake of one meal, it may not have the same effect on the total daily energy intake. Results shown by the questionnaire suggest that adding ready-to-use flavor enhancers to the cooked meal is a simple but effective way to increase daily feelings of hunger (Mathey et al, 2001).

Bellisle et al. (1991) wanted to determine if the presence of MSG could stimulate the intake of target foods served to older people. Out of a 6-month period, six weeks were selected to measure food intake for 64 institutionalized patients (average age 84 yrs) for 2 lunch menus. Each menu was presented on six occasions, and two tests were conducted 
in each of the 6 test weeks. During the first 3 test weeks Menu A was presented without MSG and Menu B was served with $0.6 \%$ MSG added to target foods (soup and starch dish). For the last 3 test weeks, the MSG additions were reversed. Foods were weighed before being presented to subjects, and plate waste was measured after the meal to determine intake (Bellisle et al, 1991).

For menu A, the intake of individual foods was not significantly different depending on the presence or absence of MSG. However, for 3 foods included in the menu intake significantly decreased over repeated presentations. Evaluation of data reveals that overall caloric intake decreased over 3 weeks when no MSG was added to the target foods while overall caloric intake did not decrease when MSG was present. A significant increase in energy intake appeared when menu B was enhanced with $0.6 \%$ MSG. This was attributed to an average increased intake of the MSG enhanced mushroom soup and mashed potatoes $(8.47 \mathrm{~g}$ and $21.67 \mathrm{~g}$, respectively) (Bellisle et al, 1991).

The different results obtained with the two menus may indicate that MSG interacts with the sensory properties of particular food substrates and is likely to be accepted more easily in certain foods than in others. Because MSG did not increase the palatability of all target foods, the authors suggest that MSG should be used in a discriminative manner (Bellisle et al, 1991).

Taken together, these studies suggest that adding flavor enhancers to meals might be an effective way to improve dietary intake in older adults. However, more conclusive data are needed in order to establish guidelines on how to use these flavor enhancers to increase intake. In addition, more studies on measurement of food consumption need to 
be done in order to separate the effects of taste function from other factors such as illness, education and income (Drewnowski, 1997).

\section{CONGREGATE MEAL SITES}

Federally supported hot lunch programs were permanently institutionalized as a nutrition program for the elderly by Title VII of the Older Americans Act of 1972. The following reasons were specified as justifications for the need of the program: a) lower incomes and poverty among elderly adults which make it difficult for them to afford adequate diets, b) the prevalence of malnutrition among minority elderly persons, c) the isolation and loneliness of many elderly people, which reduce the motivation to eat properly and, d) reduced mobility among the aged, which makes shopping for a variety of foods more difficult (U.S. Senate Select Committee on Nutrition and Human Needs, 1976).

Currently, the Older Americans Act indicates that congregate nutrition services should provide at least one hot or other appropriate meal per day and any additional meals, which the recipient of a grant or contract may elect to provide (TCSG, 2001). The law requires that these be provided in congregate settings such as churches, senior centers, or schools, or they may deliver meals to a person's home. This program may include nutrition education services and other appropriate nutrition services for older individuals. A small donation is generally asked of clients to defray the costs of the meal (Ferrini and Ferrini, 2000). It is established that these institutions solicit the advice of a dietitian or individual with comparable expertise in the planning of nutritional services and ensure that the program complies with the Dietary Guidelines for Americans. 
Programs should provide nutritious meals that contain at least one-third the RDA as established by the Food and Nutrition Board of the Institute of Medicine of the National Academy of Sciences, if the project provides 1 meal per day. In practice, sometimes these meals may constitute half or two thirds of an elder's daily intake. A minimum of $2 / 3$ RDA should be met if the project provides 2 meals and 100 percent if it provides 3 meals per day. To the maximum extent practicable, the meals should be adjusted to meet any special dietary needs of program participants (TCSG, 2001).

The Older Americans Act mandates that each state that operates such a nutrition project should provide flexibility to local nutrition providers in designing meals that are appealing to program participants. They must also encourage providers to enter into contracts that limit the amount of time meals must spend in transit before they are consumed and must comply with applicable provisions of state or local laws regarding the safe and sanitary handling of food, equipment, preparation, service, and delivery of meals to an older individual. Finally, these congregate nutrition services should provide for nutrition screening and, where appropriate, for nutrition education and counseling (TCSG, 2001).

The community-based Older Americans Act Elderly Nutrition Program benefits minority populations as well as low-income individuals who are more likely to be at nutritional risk. Elders served by the programs had lower rates of nutritional deficiencies compared to those who do not use them. Reports indicate that participants have statistically significant higher intakes of energy, calcium, zinc, and vitamin B-6 than nonparticipants (Ponza et al, 1996; Ferrini and Ferrini, 2000). 
Given the fact that the main source for daily nutrient intake for some older adults is obtained by meals provided at congregate meal sites, Burkhardt et al (1983) examined the relative importance of factors affecting attendance at congregate meal sites. Findings showed that the most important variables that affect attendance at these sites include type of food preparation, type of building and location, the amount of the suggested contribution and the competition from other sites and programs. On-site cooking was also determined to be preferred over food catered in individual portions. Thus, these variables may be important in contributing to inadequate food intake by some older adults (Burkhardt et al, 1983).

\section{VEGETABLE CONSUMPTION IN HISPANIC AMERICANS}

Older Hispanic adults are among the most rapidly growing demographic group in the United States. The Hispanic population has increased by 57.9 percent since 1990 . Currently, Cubans constitute for 3.5 percent of the whole Hispanic population in the United States. Two thirds of all Cubans reside in the state of Florida (U.S. Census Bureau, 2001).

Studies have reported that ethnicity is the major variable influencing food intake among low-income, free-living Hispanic elderly and suggested that differences in nutrient intake were associated with cultural orientation, independent of socioeconomic status (Bartholomew et al, 1990).

A study by Shea et al (1993) compared vegetable consumption among Latinos of Caribbean origin, blacks and non-Latino whites and found that vegetable intake was lowest among Puerto Ricans, Dominicans, and Cubans (Shea et al, 1993). Bartholomew 
et al also reported a low intake of all vegetables among older Hispanics (Bartholomew et al, 1990).

Most Hispanics that come to this nation are not accustomed to eating vegetables as a side dish. Also, not many of the vegetables that are seen here are familiar to them. In a study by Hampl (2001), it was reported that Hispanic participants saw an assortment of vegetables in their grocery store but did not know how to prepare them, nor did they know their nutritional value. Most of them reported that additional education would help them eat more vegetables and fruits (Hampl, 2001). Hampl (2001) discussed in his findings that low-income individuals usually tend to prioritize other foods over fruits and vegetables. Hispanic individuals faced with limited budgets prioritized meats and grains over vegetables and fruits (Hampl, 2001). Vegetables and fruits are perceived as expensive and not a priority on their shopping lists (Hampl, 2001).

Participants in this study mentioned preparing soups that included vegetables but did not mention vegetables and fruits as foods that were prepared separately. Even though some participants reported that they frequently prepared traditional foods, they did not consider them as vegetable or fruit servings until prompted by the moderator. From their point of view a serving of vegetable and fruit counted only when that food was eaten by itself, and they neglected to consider mixed dishes with tomatoes or carrots as vegetable servings (Hampl, 2001). These findings are consistent with Block et al (1995) who reported that soups and mixed dishes were important sources of vegetables among Hispanics (Block, 1995).

These studies suggest a possibility that due to cultural background, HispanicAmericans may not be as willing to accept side dishes of vegetables compared to non- 
Hispanic Americans. Also, acculturation may play an important role in dietary intake among this group. The results of these studies need to be considered when developing and implementing behavioral interventions to modify dietary practices in this population (Bartholomew et al, 1990).

\section{SUMMARY}

Inadequate dietary intake increases the risk for malnutrition in elderly adults. Risk of malnutrition increases with loss of appetite and recent changes in usual weight. One cause for concern in the elderly is the deterioration of gustatory and olfactory perception, which can potentially reduce both, the amount of food consumed and the variety of foods selected. Sensory interventions such as flavor enhancement can, in theory, compensate for age-related perceptual losses.

A number of studies have successfully used commercial flavors and monosodium glutamate (MSG) in the preparation of foods to enhance smell and taste properties and improve palatability. A limited number of studies have reported that consumption of flavor-enhanced meals may lead to an increased dietary intake, increased body weight and/or increased daily feelings of hunger, although the existing data are neither consistent or compelling.

Vegetable intake has been reported to be low among the Hispanic population. Thus, it may be possible to use flavor enhancement to increase the palatability, and therefore intake of vegetables in older Cuban American participants in congregate meal programs. 


\section{REFERENCES}

Altug T, and Demirag K. (1993). Influence of monosodium glutamate on flavor acceptability and on the reduction of sodium chloride in some ready-made soups. Chem Mikrobiol Technol Lebensmittel, 15, 161-164.

Bartholomew A, Young E, and Hazuda H. (1990). Food frequency intakes and sociodemographic factors of elderly Mexican-Americans and non-Hispanic whites. J Am Diet Assoc, 90, 1693-1696.

Bellisle F. (1999). Glutamate and the UMAMI taste: sensory, metabolic, nutritional and behavioral considerations. A review of the literature published in the last 10 years. Neurosci Biobehav Rev, 23, 423-438.

Bellisle F, Tournier A, and Louis-Sylvestre J. (1989). Monosodium glutamate and the acquisition of food preferences in a European context. Food Qual Pref, 1, 103-108.

Bellisle F, Monneuse MO, Chabert M, Larue-Achagiotis C, Lanteaume MT, and Louis-Sylvestre J. (1991). Monosodium glutamate as a palatability enhancer in the European diet. Physiol Behav, 49, 869-873.

Betts NM. (1988). Nutrition perspectives on aging. Am Behav Sci, 32, 17-30.

Block G, Norris JC, Mandel RM, and DiSogra C. (1995). Sources of energy and six nutrients in diets of low-income Hispanic American women and their children: quantitative data from HHANES, 1982-1984. J Am Diet Assoc, 95, 195-208.

Burkhardt JE, Lago AM, and Blattenberger LB. (1983). Factors affecting the demand for congregate meals at nutrition sites. Journal of Gerontology, 38(5), 614-620.

Center of Nutrition Communication. (1999). Nutrition Science: beyond the headlines. A modified food guide pyramid for people over 70 years. TUFTS Nutrition Commentator.TUFTS University School of Nutrition Science and Policy. Available at: http://commentator.tufts.edu/archive/nutrition/pyramid.html. Accessed March 14, 2002.

de Groot CPGM, van Staveren WA, and de Graaf C. (2000). Determinants of macronutrient intake in elderly people. Eur J Clin Nutr, 54(3), S70-S76.

Drewnowski A. (1997). Taste preferences and food intake. Ann Rev Nutr, 17, 237 $-253$.

Drewnowski A, Henderson SA, Driscoll A, and Rolls BJ. (1997). The dietary variety score: assessing diet quality in healthy young and older adults. $J$ Am Diet Assoc, 97(3), 266-271. 
Drewnowski A, and Gomez-Carneros C. (2000). Bitter taste, phytonutrients, and the consumer: a review. Am J Clin Nutr, 72, 1424-1435.

Duffy, V.B. (1999) Smell, taste and somatosensation in the elderly. In: Chernoff, R. Geriatric Nutrition. $2^{\text {nd }}$ ed. Maryland: Aspen Publication; S170-S205.

European Community. (1991). Reports of the Scientific Committee for Food $\left(25^{\text {th }}\right.$ series). Food-Sciences and Techniques, EUR 13416, 16.

Fanelli MT, and Stevenhagen KJ. (1985). Characterizing consumption patterns by food frequency methods: core foods and variety of foods in diets of older Americans. J Am Diet Assoc, 85, 1570-1576.

FDA. (2001). Monosodium Glutamate. Available at: http://www.fda.gov/opacom/backgrounders/msg.html Accessed Sept. 9, 2001.

Ferrini AF, and Ferrini RL. (2000). Health in the Later Years. $3^{\text {rd }}$ ed. Boston: McGraw Hill. 502 pp.

Fuke S, and Konosu S. (1991). Taste-active components of some foods: A review of Japanese research. Physiol Behav, 49, 863-868.

Geha RS, Beiser A, Ren C, Patterson R, Greenberger PA, Grammer LC, Ditto AM, Harris KE, Shaughnessy MA, Yarnold PR, Corren J, and Saxon A. (2000). Multicenter, double-blind, placebo-controlled, multiple-challenge evaluation of reported reactions to monosodium glutamate. J Allergy Clin Immunol, 106(5), 973 -980 .

Griep MI, Verleye G, Franck A, Collys K, Mets TF, and Massart DL. (1996). Variation in nutrient intake with dental status, age and odor perception. Eur J Clin Nutr, 50, 816-825.

Hampl JS, and Sass S. (2001). Focus groups indicate that vegetable and fruit consumption by food stamp-eligible Hispanics is affected by children and unfamiliarity with non-traditional foods. J Am Diet Assoc, 101(6), 685-687.

Kimura S. (1993). Taste and nutrition. Nutr Rev, 50(12), 427-433.

Koehler KM. (1994). The New Mexico aging process study. Nutr Rev, 8, S34-S37.

Kohrs MB. (1982). A rational diet for the elderly. J Clin Nut, 36, 796-802.

Lumbers M, New SA, Gibson S, and Murphy MC. (2001). Nutritional status in elderly female hip fracture patients: comparison with an age-matched home living group attending day centers. $J$ Nutr, 85, 733-740. 
Maga JA. (1983). Flavor potentiators. Crit Rev Food Sci Nutr, 18, 231-312.

Mathey MF,Siebelink E, de Graaf C, and Van Staveren WA. (2001). Flavor enhancement of food improves dietary intake and nutritional status of elderly nursing home residents. J Gerontol A Biol Sci Med Sci, 56(4), M200-205.

Mattes RD. (2002). The chemical senses and nutrition in aging: challenging old assumptions. J Am Diet Assoc, 102(2): 192-196.

Merriam-Webster's Collegiate Dictionary. 10th ed. Springfield, Mass.: MerriamWebster, 1999. 1559 pp.

Peter D. Hart Research Associates, Inc. (1993). National survey on nutrition screening and treatment for the elderly. Washington, D.C.: Peter D. Hart Research Associates, Inc.

Ponza M, Ohls JC, and Millen BE. (1996). Serving Elders at risk: The Older Americans Act Nutrition Programs, National Evaluation of the Elderly Nutrition Program, 19931995. Washington, DC: Mathematica Policy Research.

Rolls BJ. (1986). Sensory-specific satiety. Nutr Rev, 44, 93-101.

Rolls BJ, and Macdermont TM. (1991). Effects of age on sensory-specific satiety. Am J Clin Nutr, 54, 988-996.

Rolls BJ. (1989). Regulation of food and fluid intake in the elderly. In: Nutrition And The Chemical Senses In Aging. Murphy C, et.al. New York: The New

York Academy of Sciences. 217-225pp.

Rolls ET. (1997). Taste and olfactory processing in the brain and its relation to the control of eating. Crit Rev Neurobiol, 11, 263-287.

Schiffman SS. (1983). Taste and smell in disease. NEng JMed, 308, 1275-79 and 1337-1343.

Schiffman SS, and Warwick ZS. (1993). Effect of flavor enhancement of foods for the elderly on nutritional status: food intake, biochemical indices and anthropometric measures. Physiol Behav, 53, 395-402.

Schiffman SS, Sattely Miller EA, Zimmerman IA, Graham BG, and Erickson RP. (1994). Taste perception of monosodium glutamate in foods in young and elderly subjects. Physiol Behav, 56, 265-275.

Schiffman SS. (1997). Taste and smell losses in normal aging and disease. J Am Med Assoc, 278, 1357-1362. 
Schiffman SS. (1998). Sensory enhancement of foods for the elderly with monosodium glutamate and flavors. Food Rev Int, 14, 321-333.

Schiffman SS. (2000). Intensification of sensory properties of foods for the elderly. $J$ Nutr, 130(4S), 927S-930S.

Shatenstein B, Kergoat MJ, and Nadon S. (2001). Weight change, nutritional risk and its determinants among cognitively intact and demented elderly Canadians. Can J Public Health, 92(2), 143-149.

Shea S, Melnik T, Stein AD, Zansky SM, Maylahn C, and Basch CE. (1993). Age, sex, educational attainment, and race/ethnicity in relation to consumption of specific foods contributing to the atherogenic potential of diet. Prev Med, 22, 203 -218 .

Stevens JC, Cain WS, Schiet FT, and Oatley MW. (1989). Olfactory adaptation and recovery in old age. Perception, 18, 265-276.

Tarasoff L, and Kelly MF. (1993). Monosodium L-glutamate, a double blind study and review. Food Chem Toxic, 31, 1019-1035.

The Center for Social Gerontology (TCSG). (2001). Unofficial compilation of Older Americans Act Revisions. Avilable at: http://www.tcsg.org/law/oaa/reauth.htm. Accessed March 14, 2002.

U.S. Census Bureau (2001). The Hispanic Population: Census 2000 Brief. U.S. Department of Commerce. Economics and Statistics Administration. Washington, DC. Available at: http://www.census.gov/prod/2001 pubs/c2kbr01-3.pdf. Accessed March 2002.

U.S. Senate Select Committee on Nutrition and Human Needs Title VII Survey. (1976). Committee Print. U.S. Government Printing Office. Washington, DC.

Walker R, and Lupien JR. (2000). The safety evaluation of monosodium glutamate. $J$ Nutr, 130, 1049S-1052S.

Weiffenbach JM. (1984). Taste and smell perception of aging. Gerontology, 3, 137 $-146$.

WHO. (1988). Toxicological evaluation of certain food additives. Food Additive Series. 22. Cambridge: Cambridge University Press.

Wurtman JJ. (1988). Carbohydrate craving, mood changes and obesity. J Clin Psychiatry, 49, S37-S79. 
Wurtman JJ, Lieberman H, Tsay R, Nader T, and Chew B. (1988). Calorie and nutrient intakes of elderly and young subjects measured under identical conditions. J Gerontol, 43, B174-B180.

Yamaguchi S, and Takahashi C. (1984). Interactions of monosodium glutamate and sodium chloride on saltiness and palatability of a clear soup. J Food Sci, 49, 82-85. 


\section{CHAPTER III*}

\section{THE PALATABILITY OF MONOSODIUM GLUTAMATE-ENHANCED VEGETABLES AS RATED BY CUBAN-AMERICAN OLDER ADULTS \\ AT A CONGREGATE MEAL SITE}

\footnotetext{
* This chapter is being submitted to the Journal of Nutrition for the Elderly.
} 


\section{INTRODUCTION}

Chronic diseases are considered to be the most prevalent, costly, and preventable of all health problems. In the elderly, many of these conditions may be managed through a change in diet, including an adequate vegetable intake (Ferrini and Ferrini, 2000). The recommended daily servings of fruits and vegetables for the older adult population are five or more according to the modified Food Guide Pyramid for people over 70 years (Center of Nutrition Communication, 1999).

According to National Center for Chronic Disease Prevention and Health Promotion, in $1999,81 \%$ of men and $73 \%$ of women in the United States reported eating fewer than five servings of fruits and vegetables per day (CDC, 2002). Specifically, $81.5 \%$ of the Hispanic population in the state of Florida reported eating fewer than five servings of fruits and vegetables per day (CDC, 2002).

Consistent with these reports, Foote and co-workers (2000) evaluated the diet of adults over 51 years and found that more than half of the study participants consumed inadequate servings of vegetables and fruits. More importantly, greater than half of the participants reported low dietary folate intake, which can be a factor influencing cardiovascular occurrences and anemia in this population. Folate has been found to lower the atherogenic rise in plasma homocysteine levels which have been associated with premature coronary artery disease, premature occlusive vascular disease, and cerebral or peripheral vascular disease (Foote et al, 2000). Additionally, increased daily servings of uncooked vegetables will increase folate levels and decrease the incidence of megaloblastic, macrocytic anemia, which is caused by the deficiency of this vitamin in combination with cobalamin. 
Responsible for almost a million deaths among Americans each year, cardiovascular disease, principally high blood pressure, heart disease, and stroke, is the leading cause of death among both men and women across all racial and ethnic groups (CDC, 2000). The Dietary Approaches to Stop Hypertension (DASH) diet highlights the importance of fruit and vegetable consumption in controlling blood pressure. The goal of the DASH diet is to increase intakes of potassium, magnesium, calcium and fiber, moderately increase dietary protein, and reduce intake of saturated fat, total fat, and cholesterol (Sacks et al, 1995, 2001).

Diet has also been shown to affect risk of other diseases. For example, the antioxidant properties of vitamins and minerals found in vegetables are important in reducing the incidence of all types cancer, the second leading cause of death among Americans (CDC, 2000). The Administration on Aging (AoA) also encourages the increased consumption of fruits and vegetables in older people because of their high fiber content. Fiber plays a very important role in slowing the absorption rate of carbohydrates, which may be helpful in individuals with diabetes mellitus trying to regulate blood glucose levels. In 1999, diabetes accounted for 4,355 deaths in the state of Florida and the death rates were $33 \%$ higher among Hispanics than non-Hispanic whites (CDC, 2002; AOA, 1999). Fiber also functions in delaying gastric emptying and increasing transit time through the intestine, which can be helpful in older adults who suffer from constipation or other gastrointestinal disorders such as diverticulitis, irritable bowel syndrome, or colon cancer (Aldoori et al, 1998).

Food intake in the older population is affected by many physiological, psychological, and social factors that influence their food selection. Some of these 
include level of education, financial status, and living arrangements (Ferrini and Ferrini, 2000). Many older adults in the United State rely on community feeding programs, such as congregate nutrition services and Meals on Wheels, for a significant portion of their nutrient intake. Congregate nutrition services, otherwise known as congregate meal sites, were initially implemented to decrease the incidence of malnutrition among the minority elderly population, low-income older people who can't afford adequate diets, isolated and lonely elderly people with reduced motivation to eat properly, and elders whose reduced mobility made shopping for a variety of foods more difficult (U.S. Senate Select Committee on Nutrition and Human Needs, 1976). The Older Americans Act specifies that congregate nutrition services should provide at least one hot or other appropriate meal per day that contains at least one-third the RDA, as established by the Food and Nutrition Board of the Institute of Medicine of the National Academy of Sciences, meeting the established dietary guidelines for this population (Ferrini and Ferrini, 2000; TCSG, 2001). Reports indicate that participants in congregate nutrition services have statistically significant higher intakes of energy, calcium, zinc, and vitamin B-6 than nonparticipants (Ponza et al, 1996).

Older Hispanic adults are among the most rapidly growing demographic groups in the United States. Currently, Cubans constitute for 3.5 percent of the Hispanic population in the United States and two thirds of Cuban-Americans have been found to reside in the state of Florida (U.S. Census Bureau, 2001). There is some evidence indicating that Hispanics are at a potential nutrition risk due to low vegetable intake, which may in turn exacerbate the already high disease risk incidence among this population. Reports indicate that Hispanics are not accustomed to eating vegetables as a side dish and it is 
well documented that their main vegetable intake is provided by soups and mixed dishes. Vegetable intake may also be low among low-income elderly Hispanics because these are perceived as expensive and not a priority on their shopping lists (Bartholomew et al, 1990; Shea et al, 1993; Block, 1995; Hampl, 2001).

There are a number of congregate meal sites in South Florida that serve a predominantly Hispanic clientele. Some data indicate that older Hispanic people who participate in congregate nutrition services have significantly higher intakes of calories and eleven essential nutrients than do non-participants (Neyman et al, 1998). However, there are anecdotal reports of low vegetable intake at some of these sites, which suggest that the vegetables being served may not be adequately meeting the population's needs and preferences.

Studies have demonstrated that sensory acuity declines with age and that this may contribute to insufficient food intake in older people (Schiffman, 1997). Flavor amplification has been suggested as one mechanism to increase food intake and compensate for these perceptual losses (Schiffman and Warwick, 1993) although concrete evidence that flavor enhancement actually increases food intake is lacking (Mattes, 2002). A number of studies have successfully used commercial flavors and MSG, the sodium salt of the amino acid glutamic acid, in the preparation of meals to enhance smell and taste properties and improve palatability (Schiffman, 1983; Schiffman and Warwick, 1993; Bellisle et al, 1991; Mathey et al, 2001). However, some of the flavors tested in these studies are not commercially available and therefore not practical for general use. Further, scientists have not been able to give practical recommendations 
for how to apply these flavor enhancement approaches in an every day setting, such as congregate nutrition services.

The objective of this study was to evaluate whether a very simple and practical approach to enhancing vegetables with MSG would increase palatability and prospective consumption of vegetables by older Cuban Americans at a congregate meal site in South Florida. Due to the fact that MSG contains less sodium by weight than common table salt ( $\mathrm{NaCl})$ (Yamaguchi and Takahashi, 1984), flavor enhancement with this compound is a simple and inexpensive way to increase palatability of vegetables and at the same time control sodium intake in older adults. 


\section{METHODS}

\section{Subjects}

A pool of 76 Cuban-American volunteers, mean age of 76 , was recruited from the clients attending a congregate meal site in Miami, Florida. Volunteers had the opportunity to participate as little as one or as often as four times. Volunteers were excluded if they reported having asthma or a negative reaction or allergy to MSG. The mean "nutrition score" of the participants was 2.9. "Nutrition scores" are generated for all congregate nutrition program clients during yearly nutrition screening, as mandated by the Older Americans (TCSG, 2001). The Institutional Review Board at Florida International University approved this protocol and volunteers provided informed consent.

\section{Design}

Approximately 30 congregate meal clients participated in sensory testing each day. The palatability of a different vegetable pair (enhanced with MSG and nonenhanced) was evaluated each day for four days using standard protocols of hedonic testing.

Four different vegetables (beets, carrots, peas and string beans) were evaluated. These vegetables were selected for evaluation after examining the site's menus and discussing vegetable preference and plate waste information from meal site clients and staff.

The vegetables were bought at a local supermarket. The beets and string beans were fresh and the carrots and peas were purchased frozen (Publix Supermarket Brand, 
Lakeland, FL). A professional cook prepared all of the vegetables in a commercial food service facility under the direct supervision of a research assistant. The vegetables were cut in small pieces (approx. $1 / 2$ in. $x^{1 / 2}$ in.) and then steamed. After cooking the vegetables were divided, and half were enhanced using only MSG. No additional seasonings were added to the vegetables. MSG (Badia Brand, Miami, FL) was added according to product instructions in a ratio of $2 \mathrm{~g} \mathrm{MSG} / 500 \mathrm{~g}$ vegetable $(0.4 \% \mathrm{MSG})$. The MSG-enhanced and non-enhanced vegetables were stored separately and transported to the congregate meal site in an insulated container to maintain appropriate food temperature (between $140^{\circ}$ and $165^{\circ} \mathrm{F}$ ). Palatability tests were performed immediately upon arrival at the site.

\section{Palatability Test}

All testing was conducted in Spanish in consideration of the population being tested. The volunteers were tested in an activity room where stations were set with two samples (one MSG-enhanced and one non-enhanced) of the vegetable to be evaluated. In order to obtain a counterbalance design, the MSG-enhanced vegetable was in position "A" and for half of the testing, and for the other half it was in position "B". Only one research assistant knew the sample coding and the code was not broken until data were analyzed. A cup of distilled water was also provided and volunteers were instructed to rinse their mouth between samples.

Volunteers were first asked to evaluate the palatability of each vegetable sample on a 7-point hedonic scale that ranged from "I dislike it very much" to "I like it very much" with "I neither like it or dislike It," anchoring the middle. Instead of numbering 
the 7 points on the scale, there were 7 simple faces that corresponded to the verbal description. Volunteers were asked to mark their rating for the vegetable by crossing the appropriate face. The numbers (1-7) were assigned after data collection for the purposes of statistical analysis.

Following the palatability testing, prospective consumption was measured on a $100 \mathrm{~mm}$ Visual Analogue Scale (VAS). The question was asked: "If you were to be served a normal portion of this vegetable at any meal, how much of it would you be willing to eat? Mark your answer with a line across the scale." The line was anchored on the left by the word "none" and on the right by the word "all." A mark was provided at 50 $\mathrm{mm}$ to provide a visual cue of "one half." So that each volunteer would have the same concept of "normal portion," each volunteers was provided with a photograph (Abbott M, 1997) of a $1 / 2$ cup serving of mixed vegetables (carrots, peas, string beans and corn) next to a dinner fork.

Lastly, volunteers were asked to indicate which vegetable sample they preferred (A or B) in a paired preference test. The "forced choice technique" was used where a "no difference" verdict is not permitted.

\section{Statistical Analysis}

SPSS for Windows (version 10.0 for Windows, SPSS, Chicago IL) was used to analyze the palatability and prospective consumption data using paired t-tests. The forced choice preference data was analyzed using a one-sided paired comparison test for difference $(\propto=0.05$ level of significance $)$. 


\section{RESULTS}

The age, proportion of males to females, and nutrition score did not vary significantly between testing groups (Table 1). Even though the mean nutrition score bordered close to the "moderate nutritional risk" classification $(0-2=$ Good, no nutritional risk, $3-5=$ moderate nutritional risk, and 6 or more $=$ high nutritional risk), the score did not fall into this category, and the population as a whole was classified as having a normal nutritional status. Broken down by classification, $59 \%$ of the population had no nutritional risk, $38 \%$ was at a moderate nutritional risk and $12 \%$ was at a high nutritional risk.

Palatability ratings revealed that the MSG-enhanced string beans had a significantly higher palatability than the non-enhanced string beans, with an increase of 0.6 on a 7-point hedonic scale. On the other hand, there were no differences in palatability ratings between the enhanced and non-enhanced beets, carrots or peas (Table 2). The palatability ratings were consistent with the forced choice preference data. When forced to choose a preferred sample, a significantly greater number of volunteers preferred the enhanced string beans to the non-enhanced beans ( $80 \%$ vs. $20 \%$ respectively). There were no systematic preferences for either the enhanced or nonenhanced samples for the other three vegetables evaluated.

When volunteers were asked how much of each vegetable they would be willing to consume at a meal, the prospective consumption ratings for the MSG-enhanced string beans were significantly higher than the non-enhanced string beans. There were no statistical differences in prospective consumption between the enhanced and nonenhanced beets, carrots or peas. 


\section{DISCUSSION}

Results from this study demonstrate that the use of food flavor enhancement agents, such as MSG, can be used to improve palatability and to increase prospective consumption of some vegetables in older adults. Data indicated that MSG had a significant increased preference effect for one of the four vegetables tested.

These results are somewhat consistent with earlier studies that have used additional flavoring in the preparation of meals to enhance smell and taste properties and improve palatability of foods for older people (Schiffman, 1983; Schiffman and Warwick, 1993; Bellisle et al, 1991). Studies that have used MSG as a means to increase palatability and intake in older adults have found the effect to be food specific. Also, the preferred MSG concentration levels for each food varied according to age (Bellisle, 1989, 1991; Schiffman et al, 1994). These earlier data are consistent with our findings in that this study revealed the effects of MSG on palatability to be vegetable specific and that the level of favoring recommended by the package may not optimal when preparing food for older people.

Although we did not measure actual food or meal intake in this study, data that actually prove increased intake of flavor-enhanced foods are limited. Some studies have shown a transient increase in food intake and others have indicated that the addition of flavors may increase the energy intake of one meal, but not of total daily energy intake (Bellisle et al, 1991; Mathey et al, 2001). Research discussed in a 1998 review article has apparently shown that the addition of MSG to foods improved intake up to $20 \%$ in $40 / 43$ patients in a hospital setting (Schiffman, 1998). However, the original research data from 
this study have yet to be published, and other evidence that flavor enhancement increased food intake or nutritional status is not available (Mattes, 2002).

An interesting result observed in this study was that the prospective consumption and palatability ratings were relatively high for all the vegetables tested in this study. Volunteers indicated, for each of the vegetables, that they were willing to consume more than half the $1 / 2$ cup portion. These data seemed to indicate a greater acceptance for vegetables than one would expect based on consumption data that has shown lower acceptance and intake of vegetables as a side dish in Hispanic populations (Bartholomew et al, 1990; Shea et al, 1993).

Flavor enhancement with MSG is only one of many mechanisms used to increase palatability of vegetables. This study suggests that older adults may not find the palatability of some vegetables to be improved by MSG and that optimal flavor enhancement cannot be achieved by adding the same amount of MSG to every vegetable. Therefore, different MSG concentration levels need to be tested in order to determine which one is more effective in increasing the palatability of each different vegetable.

MSG is a simple and inexpensive approach to increase the palatability of foods by intensifying the characteristic chemosensory properties of each food. Safety concerns have resulted in some hesitation to use this compound. However, the Food and Drug Administration (FDA), has classified MSG as "generally recognized as safe," or GRAS. The FDA have concluded that MSG poses no threat to the general public but that reactions of brief duration might occur in some people (FDA/ Gov Doc, 2001).

Other methods for increasing palatability of vegetables may include the use of herbs and spices, which add new flavors to foods rather than intensify the original 
properties of foods. These have been used in numerous ways and combinations. Their effect gives the consumer an increased variety of food selection by creating new ways to prepare the same food. However, the use and repeated exposure of some of these herbs and spices have been found to cause gastric discomfort in some people (Schiffman, 2000).

The addition of sauces and dairy products in the preparation of vegetables may be another mechanism to increase their consumption. Additionally, the use of dairy products may help by providing some of the other micronutrients (such as calcium and vitamin D) and calories that have been found to be deficient in this population (Foote et al, 2000). The cost of dairy products and other ingredients, as well as lactose intolerance present in many older adults, may be an obstacle for utilizing this approach.

Congregate meal site staff may want to consider serving more types of vegetable salads, with a variety of flavorful dressings. Vegetables can be marinated or cooked, chilled and incorporated into a variety of salad preparations that can be flavored with a great variety of dressings. This form of preparation may be helpful in complying with the Older Americans Act, which states that congregate meal food providers should limit the amount of time meals spend in transit before they are consumed (TCSG, 2001). One of the reasons for this is that many foods lose their originally intended palatability characteristics due to the extended time that elapses from preparation to consumption.

As the literature has mentioned, soups and mixed dishes have been found to be an important source of vegetable intake in Hispanics, as well as many other minority groups (Block, 1995). It is logical that vegetables in soups and mixed dishes would also be well accepted at congregate nutrition services. The increased incorporation of vegetables into 
combination dishes is one way meet the requirements established by the Older Americans Act that $1 / 3$ of the RDA be provided in each meal.

In conclusion, there is no single best way to increase palatability of vegetables for older adults. Ethnic norms need to be studied and considered when preparing vegetable dishes. Also, the nature of the vegetables themselves needs to be considered in order to individually determine the best approach for preparation. This study concludes that MSG may be one of the possible approaches to increase palatability and consumption of some vegetables. However, data suggest that the effect is vegetable specific and that optimal flavor enhancement cannot be achieved by adding the same amount of MSG to every vegetable. Further studies need to be conducted in order to determine the effect of different amounts of MSG on different vegetables. 
TABLE 1. Descriptive Characteristics of Volunteers

\begin{tabular}{lccccc}
\hline $\begin{array}{l}\text { Vegetable } \\
\text { Tested }\end{array}$ & n & Female (\%) & Male (\%) & Age (yrs) $^{*}$ & Nutrition Score $^{*-}$ \\
\hline Beets & 31 & 68 & 32 & $76 \pm 1.3$ & $2.9 \pm 0.3$ \\
String Beans & 30 & 73 & 27 & $74 \pm 2.5$ & $2.8 \pm 0.4$ \\
Carrots & 32 & 88 & 12 & $75 \pm 1.9$ & $2.8 \pm 0.3$ \\
Peas & 30 & 87 & 13 & $77 \pm 2.0$ & $3.0 \pm 0.4$ \\
\hline${ }^{*}$ Variable represents mean \pm SD & & &
\end{tabular}


TABLE 2. Palatability Ratings, Prospective Consumption and Preference of Vegetables MSG-enhanced and Non-enhanced

\begin{tabular}{|c|c|c|c|c|c|c|}
\hline \multirow[t]{2}{*}{ Vegetable } & \multicolumn{2}{|c|}{ Palatability Ratings ${ }^{*}$} & \multicolumn{2}{|c|}{ Prospective Consumption (mm) } & \multicolumn{2}{|c|}{ Paired Preference $(\%)$} \\
\hline & $\begin{array}{l}\text { MSG- } \\
\text { enhanced }\end{array}$ & Non-enhanced & $\begin{array}{c}\text { MSG- } \\
\text { enhanced }\end{array}$ & Non-enhanced & $\begin{array}{c}\text { MSG- } \\
\text { enhanced }\end{array}$ & Non-enhanced \\
\hline Beets & $5.7 \pm 1.2$ & $5.7 \pm 1.1$ & $67 \pm 31.9$ & $64 \pm 28.2$ & 45 & 55 \\
\hline String Beans & $6.0 \pm 1.4^{\dagger}$ & $5.4 \pm 1.4$ & $70 \pm 30.2^{\dagger+}$ & $54 \pm 33.5$ & $80^{\dagger+}$ & 20 \\
\hline Carrots & $6.3 \pm 0.9$ & $6.1 \pm 1.0$ & $73 \pm 24.4$ & $68 \pm 29.0$ & 66 & 34 \\
\hline Peas & $5.9 \pm 1.3$ & $5.8 \pm 1.4$ & $74 \pm 25.8$ & $66 \pm 28.5$ & 60 & 40 \\
\hline
\end{tabular}




\section{REFERENCES}

Abbott M. (1997). Portion Photos of Popular Foods. The American Dietetic Association and Center for Nutrition Education, University of Wisconsin-Stout. $131 \mathrm{pp}$.

Administration on Aging (1999). National Institute on Age Page: Constipation. Available at: http://www.aoa.dhhs.gov/aoa/pages/agepages/constapn.htmll. Accessed March 18, 2002.

Aldoori W, Giovannucci E, Rockett H, Sampson L, Rimm E, and Willett W. (1998). A prospective study of dietary fiber types and symptomatic diverticular disease in men. $J$ Nutr, 128: 714-719.

Bartholomew A, Young E, and Hazuda H. (1990). Food frequency intakes and sociodemographic factors of elderly Mexican-Americans and non-Hispanic whites. $J$ Am Diet Assoc, 90, 1693-1696.

Bellisle, F. (1989). Glutamate and the UMAMI taste: sensory, metabolic, nutritional and behavioral considerations. A review of the literature published in the last 10 years. Neurosci Biobehav Rev, 423-438.

Bellisle F, Monneuse MO, Chabert M, Larue-Achagiotis C, Lanteaume MT, and LouisSylvestre J. (1991). Monosodium glutamate as a palatability enhancer in the European diet. Physiol Behav, 49, 869-873.

Block G, Norris JC, Mandel RM, and DiSogra C. (1995). Sources of energy and six nutrients in diets of low-income Hispanic American women and their children: quantitative data from HHANES, 1982-1984. J Am Diet Assoc, 95,195-208.

Center of Nutrition Communication. (1999). Nutrition Science: beyond the headlines. A modified food guide pyramid for people over 70 years. TUFTS Nutrition Commentator. TUFTS University School of Nutrition Science and Policy. Available at: http://commentator.tufts.edu/archive/nutrition/pyramid.html. Accessed March 14, 2002.

Drewnowski A. (1997). Taste preferences and food intake. Annu Rev Nutr, 17,237-253.

FDA. (2001). Monosodium Glutamate. Available at: http://www.fda.gov/opacom/backgrounders/msg.html Accessed Sept. 9, 2001.

Ferrini AF, and Ferrini RL. (2000). Health in the Later Years. $3^{\text {rd }}$ ed. Boston: McGraw Hill. 502 pp.

Foote JA, Guiliano AR, and Harris RB. (2000). Older adults need guidance to meet nutritional recommendations. $J$ Am Coll Nutr, 19(5): 628-640. 
Hampl JS, and Sass S. (2001). Focus groups indicate that vegetable and fruit consumption by food stamp-eligible Hispanics is affected by children and unfamiliarity with non-traditional foods. J Am Diet Assoc, 101(6), 685-687.

Mathey MF, Siebelink E, de Graaf C, and Van Staveren WA. (2001). Flavor enhancement of food improves dietary intake and nutritional status of elderly nursing home residents. J Gerontol A Biol Sci Med Sci, Apr, 56(4), M200-205.

Mattes RD. (2002). The chemical senses and nutrition in aging: challenging old assumptions. J Am Diet Assoc, 102(2): 192-196.

National Center for Chronic Disease Prevention and Health Promotion (CDC). (2000). Chronic Disease Prevention. Available at: http://www.cdc.gov/nccdphp/major.htm Accessed March 15, 2002.

National Center for Chronic Disease Prevention and Health Promotion (CDC). (2002). Chronic Disease Prevention: The burden of chronic diseases and their risk factors. National and State Perspectives 2002. Available at:

http://apps.nccd.cdc.gov/BurdenBook/ Accessed March 15, 2002.

Neyman MR, Block G, Johns M, Sutherlin Jm, McDonald RB, and Zidenberg-Cherr S. (1998). Effect of participation in congregate meal site programs on energy and nutrient intakes of Hispanic seniors. J Am Diet Assoc, 98: 1460-1462.

Ponza M, Ohls JC, and Millen BE. (1996). Serving Elders at risk: The Older Americans Act Nutrition Programs, National Evaluation of the Elderly Nutrition Program, 19931995. Washington, DC: Mathematica Policy Research.

Rolls BJ, and Macdermont TM. (1991). Effects of age on sensory-specific satiety. Am J Clin Nutr, 54, 988-996.

Sacks FM, Obarzanek E, Windhauser MM, Svetkey LP, Vollmer WM, Lin PH, McCullough M, Karanja N, Steele P, Proschan MA, Evans MA, Appel LJ, Bray JA, Vogt TM, and Moore TJ. (1995). Rationale and design of the Dietary Approaches to Stop Hypertension Trial (DASH): a multicenter controlled feeding study of dietary patterns to lower blood pressure. Ann Epidemiol, 5, 108-118.

Sacks FM, Svetkey LP, Vollmer WM, Appel LJ, Bray JA, Harsha D, Obarzanek E, Conlin PR, Miller ER, Simons-Morton DG, Karanja N, and Lin PH. (2001). Effects on blood pressure of reduced dietary sodium and the Dietary Approaches to Stop Hypertension (DASH) diet. N Engl J Med, 344(1), 3-10.

Schiffman, SS. (1983). Taste and Smell in Disease. N Engl J Med, 308(22), 1275 -1279 and $1337-1343$. 
Schiffman SS, and Warwick ZS. (1993). Effect of flavor enhancement of foods for the elderly on nutritional status: food intake, biochemical indices and anthropometric measures. Physiol Behav, 53(2), 395-402.

Schiffman SS, Sattely Miller EA, Zimmerman IA, Graham BG, and Erickson RP. (1994). Taste perception of monosodium glutamate in foods in young and elderly subjects. Physiol Behav, 56, 265-275.

Schiffman SS. (1997). Taste and smell losses in normal aging and disease. J Am Med Assoc, 278, 1357-1362.

Schiffman SS. (1998). Sensory enhancement of foods for the elderly with monosodium glutamate and flavors. Food Rev Int, 14, 321-333.

Schiffman SS. (2000). Intensification of sensory properties of foods for the elderly. $J$ Nutr, 4, 927S-930S.

Shea S, Melnik T, Stein AD, Zansky SM, Maylahn C, and Basch CE. (1993). Age, sex, educational attainment, and race/ethnicity in relation to consumption of specific foods contributing to the atherogenic potential of diet. Prev Med, 22,203-218.

The Center for Social Gerontology (TCSG). (2001). Unofficial compilation of Older Americans Act Revisions. Avilable at: http://www.tcsg.org/law/oaa/reauth.htm. Accessed March 14, 2002.

U.S. Census Bureau (2001). The Hispanic Population: Census 2000 Brief. U.S. Department of Commerce. Economics and Statistics Administration. Washington, DC. Available at: http://www.census.gov/prod/2001pubs/c2kbr01-3.pdf. Accessed March 15, 2002.

U.S. Senate Select Committee on Nutrition and Human Needs Title VII Survey. (1976). Committee Print. U.S. Government Printing Office. Washington, DC.

Yamaguchi S, and Takahashi C. (1984). Interactions of monosodium glutamate and sodium chloride on saltiness and palatability of a clear soup. J Food Sci, 49, 82-85. 


\section{APPENDICES}




\section{MUESTRA "A"}

\section{INSTRUCCIONES:}

I. Seleccione con una $X$ la opción que mejor describa su opinión acerca del sabor de cada muestra.

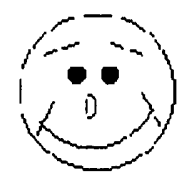

iMe gusta mucho!

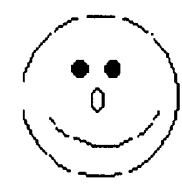

Me gusta

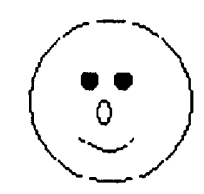

Me gusta poco

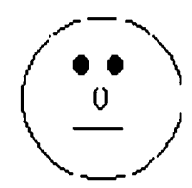

Ni me gusta ni me disgusta

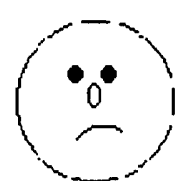

Me disgusta poco
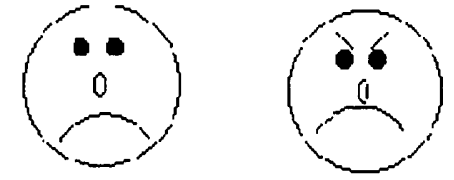

Me iMe disgusta disgusta mucho!

II. Si me sirvieran una porcion normal de esta verdura, ¿cuanto de esta estaría yo dispuesto(a) a comer? Marque su respuesta con una raya en la línea.

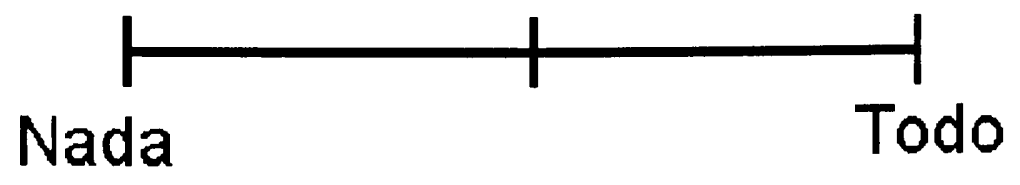




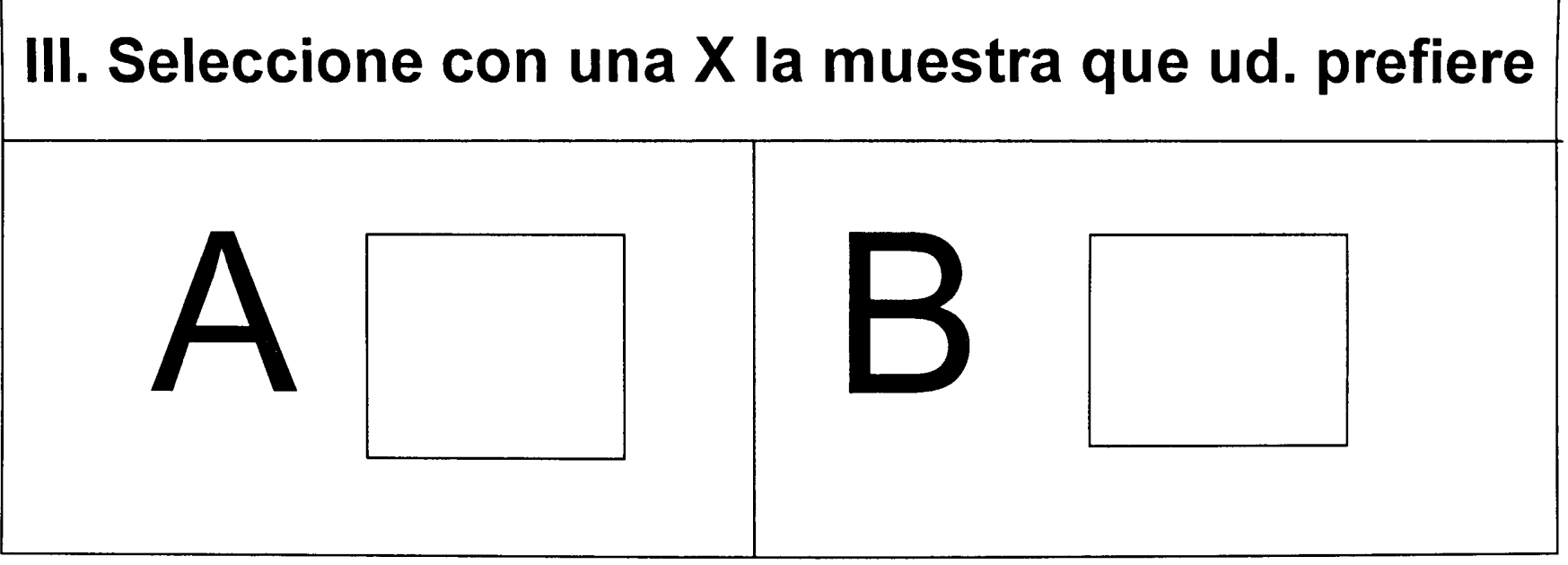




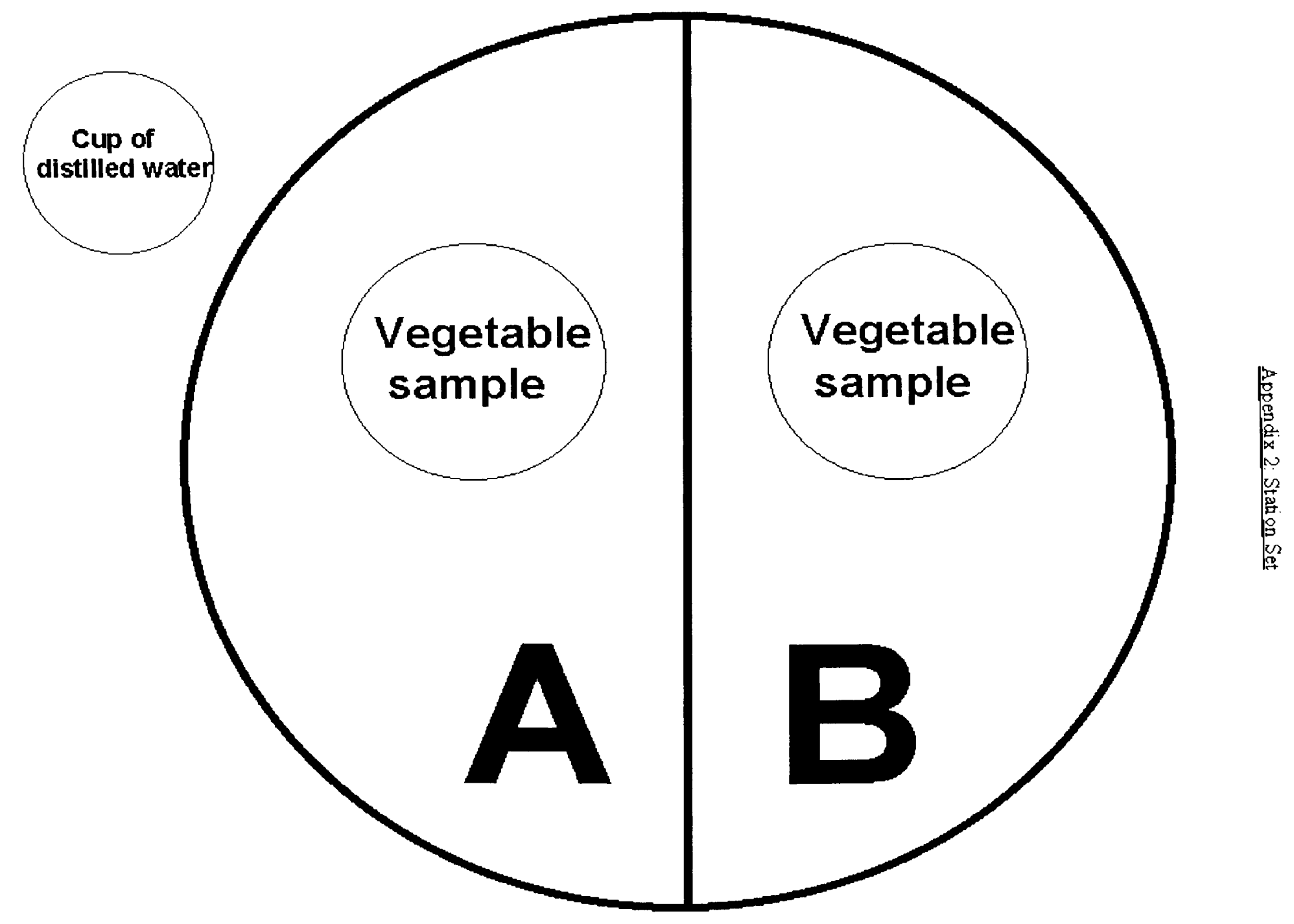




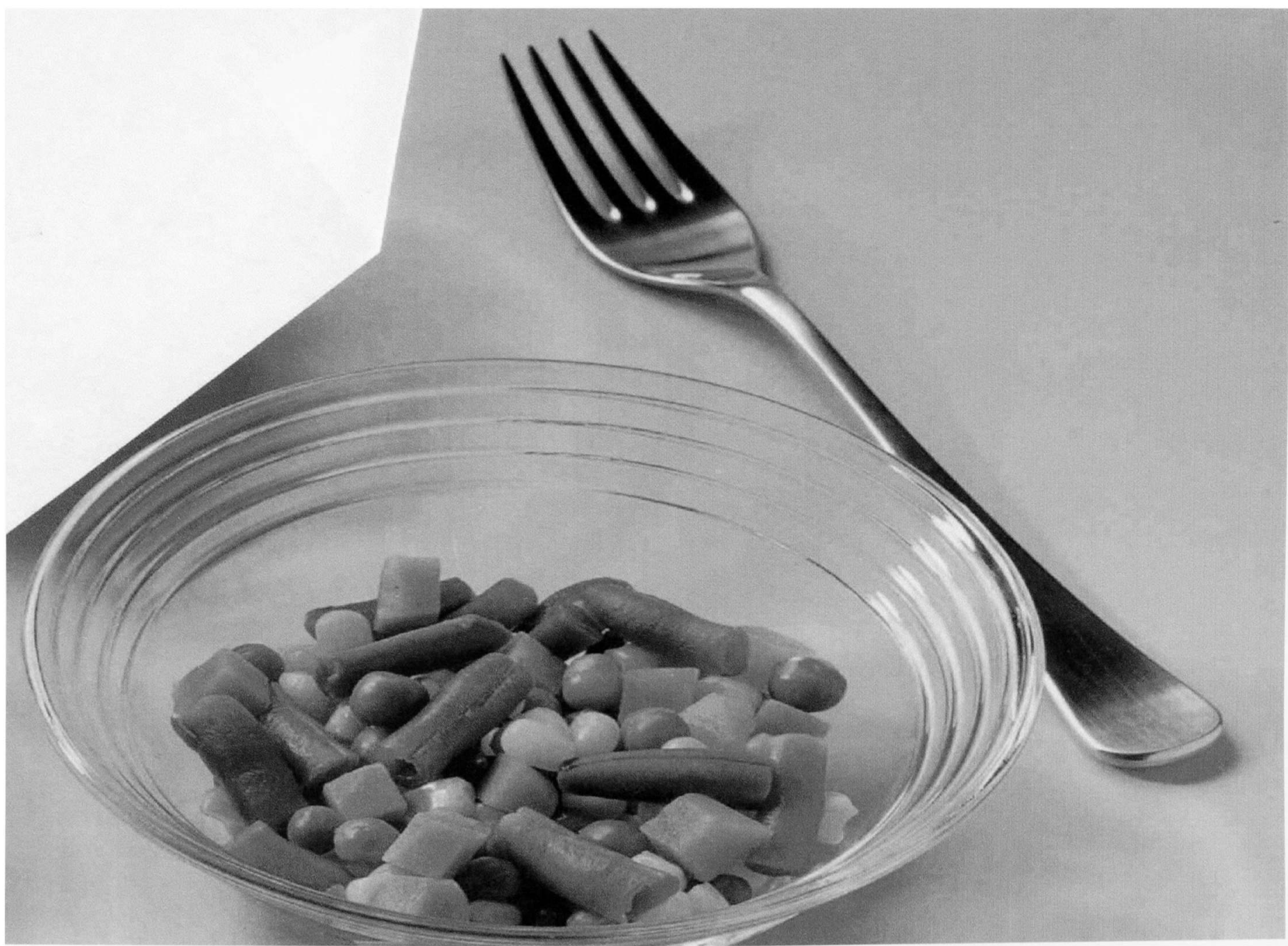

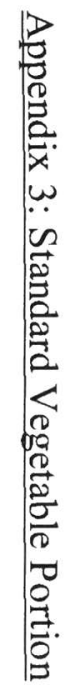

